\title{
Эффективность углеадсорбционной очистки стоков с территории коксохимического производства
}

\author{
Зенькова Е.В. ${ }^{1}$, Клушин В.Н. ${ }^{1}$, Зубахин Н.П. ${ }^{2}$, Семенов Г.М. ${ }^{1}$, \\ Осипова А.С. ${ }^{1}$, Шабалина А.С. ${ }^{1}$ \\ ${ }^{1}$ РХТУ им. Д.И. Менделеева, Москва \\ ${ }^{2}$ Московский коксогазовый завод, Видное, Московская область
}

Поступила в редакцию 4.05.2016 г.

\begin{abstract}
Оценена сопоставительная эффективность очистки от органических примесей сточных вод с территории коксохимического производства ОАО «Москокс» активным углем ДПУ и углями отечественного производства марок БАУ-А, АГ-З, СКТ и МеКС. Результатами изучения процессов, реализованных интенсивным перемешиванием зерен адсорбентов со сточной водой и фильтрованием последней через стационарный слой этих зерен, констатирована высокая конкурентоспособность угля ДПУ в решении задачи ее глубокой очистки.
\end{abstract}

Ключевые слова: отходы, активные угли, удельная поверхность, пористость, сточные воды, загрязняющие вещества органической природы, адсорбция

\section{Efficiency of active carbon adsorptive purification of wastewaters from territory of coke-chemical manufacture}

\author{
Zenkova E.V. ${ }^{1}$, Klushin V.N. ${ }^{1}$, Zubakhin N.P. ${ }^{2}$, Semenov G.M. ${ }^{1}$, \\ Osipova A.S. ${ }^{1}$, Shabalina A.S. \\ ${ }^{I}$ Mendeleev University of Chemical Technology of Russia, Moscow \\ ${ }^{2}$ Moscow Coke-Gas Works, Vidnoe, Moscow region
}

\begin{abstract}
The porous structure and the adsorptive properties of the DPU active coal received by pyrolysis and the subsequent steam-gas activation from the formed granules of raw paste - a product of mixture of flour of the wood-shaving plate (WSP) with vitriolic solution of waste soft polyurethane foam (PPU) are characterized. Technical characteristics of DPU coal are compared with those of coals of domestic industrial production of the BAU-A, AG-3, SKT brands and MeKS. Volumes mesoporous and mesoporous of the DPU active coal are estimated with attraction of the BJH method and Dubinin-Radushkevich's equation respectively in relation to balance of low-temperature adsorption / desorption of nitrogen, at $77 \mathrm{~K}$ and the relative pressure of $\mathrm{R} / \mathrm{R}_{\mathrm{o}}$ from 0 to 1 , to RHTU studied with attraction of the automatic analyzer of a specific surface and porosity of Gemini VII of Micromeritics firm (USA). Rational conditions of processing of the called drains at intensity of hashing, the corresponding $R_{\mathrm{em}}=5 \cdot 10^{5}$, a dose of adsorbent of $1 \mathrm{~g} / \mathrm{dm}^{3}$ and duration of contact of phases of 25-30 min. In comparable conditions efficiency of cleaning of organic pollution of sewage from the territory of coke-chemical production of JSC Moscow Coke and Gas Plant is revealed by the called active coals. Results of studying of the processes realized by intensive hashing of grains of adsorbents with waste water and filtering of the last through a stationary layer of these grains have stated high competitiveness of DPU coal in the solution of a problem of her deep cleaning with a possibility of dumping into reservoirs of fishery use. Efficiency of use for the solution of a problem of removal from the called drains of organic impurity of BAU coal at hour contact of phases extent of cleaning about 53.6\%. Coals of the SKT and AG-3 brands are more effective, providing with the same duration of processes approximately identical residual concentration of organic carbon at the level of $9 \mathrm{mg} / \mathrm{dm}^{3}$ (extent of cleaning about $80 \%$ ). The best results are shown by the DPU coal settling the absorbing ability to half-hour contact of phases, leading to the residual
\end{abstract}


content of organic carbon $0.9 \mathrm{mg} / \mathrm{dm}^{3}$ and showing extent of cleaning about $97.8 \%$. A little surpassing these results are provided by use of the MeKS coal having considerably sizes of volume of micropores, big in comparison with DPU coal (on 45-70 \%) and a specific surface (on 51-97 \%). Adsorptive ability causing the same duration of interaction of phases provides about $98.8 \%$ cleaning. Realization of receiving the DPU active coal in factory scales can promote the solution of a triune problem of extension of the nomenclature of carbon adsorbents, effective involvement in production of goods of the MSW components and reductions of negative impact of the last on environment.

Keywords: waste, active coals, specific surface, porosity, waste water, organic pollutants, adsorption.

\section{Введение}

Ужесточение природоохранного законодательства обусловливает возрастание актуальности изыскания решения многих проблем в области охраны окружающей среды, в ансамбль которых входят, в частности, задачи эффективного вовлечения в материальное производство мебельной компоненты ТБО и глубокой очистки сточных вод перед их сбросом в природные водоемы [1]. Один из вариантов, как представляется, полезного в практическом плане подхода к решению таких задач охарактеризован ниже на примере использования для очистки сточных вод с территории коксохимического производства ОАО «Москокс» активного угля, обозначенного ниже литерами ДПУ и полученного методом парогазовой активации продукта пиролиза формованной сырьевой композиции из муки ДСП и раствора в серной кислоте фрагментов мягкого пенополиуретана (ППУ).

Реализация производства такого угля по технологии, разработанной в РХТУ им. Д.И. Менделеева [2-4], в условиях значительного спроса на эту продукцию обещает существенные позитивные сдвиги в вопросах эффективного решения проблемы обращения с ТБО в части последних, представленной вышедшей из эксплуатации деревянной бытовой и офисной мебелью и ее фрагментами и достигающей в городах и населенных пунктах РФ 5 \% массы этих отходов [5, 6].

Сточные воды с территории коксохимического производства ОАО «Москокс» содержат множество загрязняющих веществ как органической, так и неорганической природы. Согласно [1] максимальные содержания в этих стоках нефтепродуктов и фенолов превышают величины, регламентируемые действующим законодательством для воды водоемов рыбохозяйственного назначения [7], примерно в 5-8 и 1-3 раза соответственно, по другим загрязнениям такие превышения не столь существенны. Таким образом, несмотря на небольшое в целом содержание нефтепродуктов (0.290.40 мг/ дм $\left.{ }^{3}\right)$ и фенолов $(0.003$ мг/ дм³ $)$, именно их удаление из стоков представляет приоритетную для предприятия задачу. При этом низкие концентрации целевых компонентов предопределяют целесообразность использования для очистки стоков лишь заключительной стадии из обычно практикуемой оптимальной последовательности процессов физико-химической обработки «коагуляция - флотация/отстаивание - фильтрование/декантация - сорбция» [1].

В РФ для адсорбционного извлечения нефтепродуктов из сточных вод используют (путем фильтрования жидкости через слой зерен адсорбента определенной высоты или ее перемешивания с ними в течение необходимого времени) главным образом зерненые активные угли промышленного производства марок АГ-3 (каменноугольная основа), СКТ (торф), МеКС (косточковое сырье, модифицированное полимеризующимися добавками), БАУ-А (древесина березы) [8].

Целью настоящей работы является обоснование преимуществ использования полученного из компонентов ТБО нового активного угля ДПУ в решении задач защиты гидросферы на примере очистки сточных вод с территории коксохимического производства ОАО «Москокс». 


\section{Эксперимент}

Для сопоставительной оценки эффективности очистки представительной пробы стоков с территории коксохимического производства ОАО «Москокс» использованы образец активного угля ДПУ, полученный из формованной сырьевой композиции, состав которой выражает соотношение $\left(\mathrm{m}_{\Pi п у:} \mathrm{m}_{\mathrm{H} 2 \mathrm{SO} 4}\right): \mathrm{m}_{\text {дсп }}=(1: 1.6): 0.7$ [4], и образцы перечисленных выше углей, предоставленные авторам одной из лабораторий ОАО «Электростальское НПО «Неорганика».

Объемы мезо- и микропор активного угля ДПУ оценены с привлечением метода ВЈН и уравнения Дубинина-Радушкевича соответственно применительно к равновесию низкотемпературной адсорбции/десорбции азота, при 77 К и относительном давлении $\mathrm{P} / \mathrm{P}_{\text {o }}$ от 0 до 1 , изученному центром коллективного пользования РХТУ им. Д.И. Менделеева с привлечением автоматического анализатора удельной поверхности и пористости Gemini VII фирмы Micromeritics (США). Сведения о пористой структуре других адсорбентов охарактеризованы по данным $[4,9,10]$ и сопоставлены с аналогичными показателями угля ДПУ в табл. 1.

Данные табл. 1 свидетельствуют, что активный уголь ДПУ характеризует величина удельной поверхности $\left(\mathrm{S}_{\mathrm{yд}}\right)$ по БЭТ практически идентичная таковой актив-

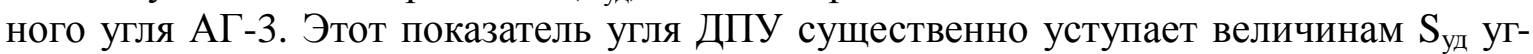
лей МеКС и СКТ (производство последнего отечественной промышленностью прекращено), но практически вдвое превосходит величину $S_{\text {уд }}$ угля БАУ-А. Отличительной особенностью угля ДПУ является практическое равенство объемов его микро- и мезопор, причем величина последних значительно превышает таковые охарактеризованных углей промышленного производства. Это обстоятельство указывает на принадлежность активного угля ДПУ к углям смешанной пористой структуры, способным извлекать из растворов молекулы разных размеров.

Таблица 1. Сравнительная характеристика пористой структуры использованных активных углей

\begin{tabular}{|c|c|c|c|c|c|}
\hline Марка угля & \multirow{2}{*}{$\begin{array}{c}\text { Суммарный } \\
\text { объем пор, } \mathrm{cm}^{3} / \Gamma\end{array}$} & \multicolumn{2}{|c|}{ Объем, $\mathrm{cm}^{3} / \Gamma$} & $\begin{array}{c}\text { Золь- } \\
\text { ность, \% }\end{array}$ & $\begin{array}{c}\text { Удельная } \\
\text { поверхность, }{ }^{2} / \Gamma\end{array}$ \\
\cline { 3 - 4 } ДПУ & $0.80-0.82$ & $0.38-0.40$ & $0.37-0.38$ & 10 & $810-1060$ \\
\hline АГ-3 & $0.75-0.95$ & $0.25-0.28$ & $0.10-0.15$ & 15 & $800-1000$ \\
\hline СКТ & $0.83-0.95$ & $0.40-0.48$ & $0.18-0.19$ & $15-20$ & $1200-1500$ \\
\hline МеКС & $0.90-1.24$ & $0.55-0.68$ & $0.15-0.28$ & 2 & 1600 \\
\hline БАУ-А & $1.65-1.80$ & $0.22-0.25$ & $0.08-0.1$ & 6 & $400-500$ \\
\hline
\end{tabular}

Примечание: $\mathrm{V}_{\text {ми }}$ - объем микропор, $\mathrm{V}_{\text {ме }}$ - объем мезопор.

Подготовка адсорбентов к исследованиям осуществлена дроблением их зерен с рассевом продуктов и выделением целевых фракций крупностью 1-2 мм.

Исследования кинетики адсорбции органических загрязняющих веществ из сточной воды активными углями проведены при интенсивном перемешивании твердой и жидкой фаз $\left(\mathrm{Re}_{\mathrm{M}} \sim 10000\right)$ и температуре $22 \pm 2{ }^{\circ} \mathrm{C}$ с периодическим отбором проб водно-угольной суспензии и максимально быстрым разделением их фаз под вакуумом с использованием фильтра Шотта, фиксированного в колбе Бунзена.

Оценочным показателем содержания органических загрязняющих веществ в сточной воде до и после ее углеадсорбционной обработки служила концентрация органического углерода (ОУ), определяемая путем газохроматографического детек- 
тирования. Наряду с этим, так как одним из наиболее распространенных методов оценки степени загрязненности сточных вод является показатель химического потребления кислорода (ХПК, мг/дм³) [11], в ряде определений в качестве арбитражного был использован бихроматный метод оценки этого показателя.

Адсорбция в динамических условиях изучена лишь для близких по природе активных углей ДПУ и БАУ при тех же температурах. Высота слоя зерен обоих углей, размещенных в стеклянных колонках внутренним диаметром 1.86 см и длиной $30 \mathrm{~cm}$, составляла $25 \mathrm{~cm}$. Предварительно взвешенный образец активного угля засыпали в колонку на слой стекловаты толщиной 2-3 мм. Самотечный расход сточной воды через каждую из угольных загрузок обеспечивали постоянным и равным 3.14 дм $3 /$ час (11.56 м/час), поддерживая высоту ее слоя в колонке над углем в пределах 15-20 мм. Из выходящей из слоя зерен угля жидкости периодически отбирали образцы, пропуская их через вакуумируемый фильтр Шотта и подвергая затем фильтрат анализу.

Величину работающего слоя $L_{o}$, характеризующую качество используемого поглотителя в исследуемом процессе очистки, определяли с использованием уравнения Майклса-Трейбла [12]:

$$
L_{0}=L \cdot \frac{\Delta \tau}{\tau_{p}-(1-\varphi) \cdot \Delta \tau}
$$

где $\Delta \tau$ - разность времени между появлением за слоем зерен угля исходной концентрации анализируемых загрязняющих веществ $\tau_{p}$ и их проскоковой концентрации $\tau_{n p}$, определяемой чувствительностью используемого аналитического метода; $\varphi$ - коэффициент симметричности выходной кривой.

\section{Обсуждение результатов}

Результаты изучения кинетики адсорбционной очистки сточной воды с использованием фракции 1-2 мм зерен активного угля ДПУ дозами $0.5,1$ и 2 г/дм ${ }^{3}$ в охарактеризованных выше условиях представлены в табл. 2.

Таблица 2. Кинетика углеадсорбционной обработки стока

\begin{tabular}{|c|c|c|c|c|}
\hline \multirow[t]{2}{*}{$\begin{array}{c}\text { № } \\
\text { пробы }\end{array}$} & \multirow{2}{*}{$\begin{array}{c}\text { Время переме- } \\
\text { шивания, } \\
\text { мин. }\end{array}$} & \multicolumn{3}{|c|}{$\begin{array}{c}\text { Остаточная концентрация (мг/ дм³) органического углерода } \\
\text { (числитель) и степень (в \%) очистки (знаменатель) при дозе } \\
\text { ДПУ (г/дм³): }\end{array}$} \\
\hline & & 0.5 & 1 & 2 \\
\hline 1 & 0 & $41.15 / 0.00$ & $41.15 / 0.00$ & $41.15 / 0.00$ \\
\hline 2 & 5 & $25.60 / 37.79$ & $16.20 / 60.63$ & $10.50 / 74.48$ \\
\hline 3 & 10 & $19.20 / 53.34$ & $7.10 / 82.74$ & $4.60 / 88.82$ \\
\hline 4 & 15 & $18.00 / 56.26$ & $4.00 / 90.27$ & $1.50 / 96.35$ \\
\hline 5 & 20 & $15.30 / 62.82$ & $3.60 / 91.25$ & $1.10 / 97.33$ \\
\hline 4 & 25 & $8.60 / 79.10$ & $1.10 / 97.33$ & $0.90 / 97.81$ \\
\hline 5 & 30 & $5.00 / 87.11$ & $1.10 / 97.33$ & $0.90 / 97,81$ \\
\hline 6 & 35 & $5.00 / 87.11$ & $1.10 / 97.33$ & $0.90 / 97.81$ \\
\hline
\end{tabular}

Данные табл. 2. свидетельствуют, что максимальную степень очистки (97.81\%) обеспечивает доза адсорбента 2 г/ дм³ при перемешивании водно-угольной суспензии в турбулентном режиме в течение 25 мин. Наряду с этим вдвое меньшая доза угля за то же время обусловливает сокращение характеризуемого загрязнения стока на весьма близкую величину $(97.33 \%)$, что из практических соображений предопределяет целесообразность выбора в качестве оптимальных параметров очистки 
дозу поглотителя 1 г/дм³ и 25-минутное время контакта фаз. Следует подчеркнуть, что приведенная ниже информация позволяет констатировать соответствие остаточного содержания органических загрязняющих веществ в обработанных в названных оптимальных условиях стоках действующим санитарным нормативам.

Наряду с этим с целью сравнения в работе в аналогичных условиях контакта фаз использованы образцы активных углей заводского производства марок АГ-3, СКТ, МеКС и БАУ-А дозой 1 г/ дм³. Результаты их взаимодействия с той же сточной водой сопоставлены с таковыми, охарактеризованными выше, на рис. 1.

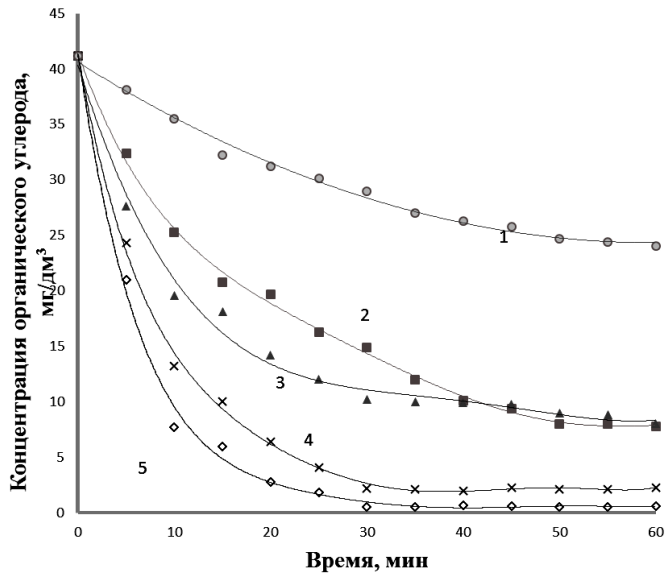

Рис. 1. Кинетика очистки сточной воды активными углями

(1 - БАУ, 2 - АГ-3, 3 - СКТ, 4 - ДПУ, $5-\mathrm{MeKC})$

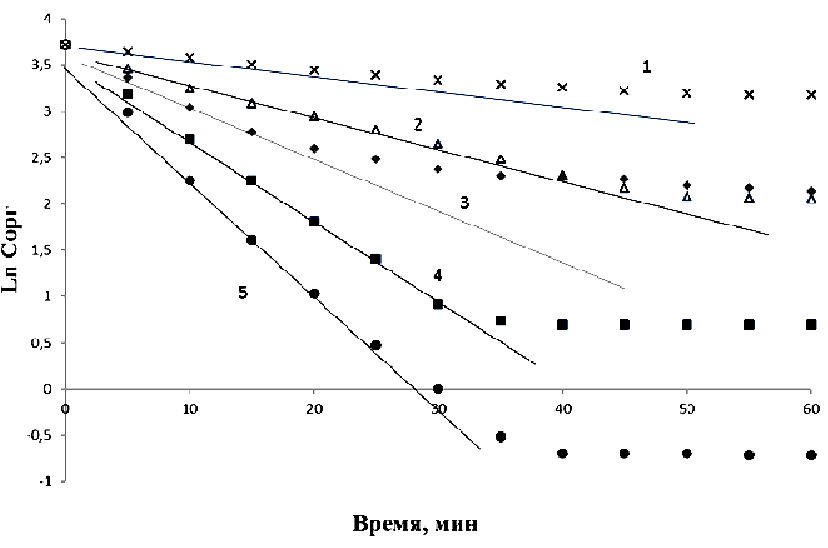

Рис. 2. Зависимость натурального логарифма концентрации органического углерода от времени контакта со сточной водой активных углей БАУ (1), АГ-3 (2), СКТ (3), ДПУ (4) и МеКС (5)

На основании охарактеризованных кинетических кривых получены зависимости, представленные на рис. 2 и позволяющие оценку величин константы $\mathrm{k}$ уравнения $\ln \mathrm{C}=\ln \mathrm{C}_{\mathrm{o}}-\mathrm{k} \tau$, формально описывающего изученные зависимости концентрации органического углерода от времени. Эти величины составляют: 0.0487 для угля ДПУ, 0.0281 для АГ-3, 0.0235 для СКТ, 0.072 для МеКС и 0.088 для БАУ-А.

Охарактеризованные результаты свидетельствуют о низкой эффективности использования для решения задачи удаления из названных стоков органических примесей угля БАУ: при часовом контакте фаз степень очистки не превышает $53.6 \%$. Угли марок СКТ и АГ-3 более эффективны, обеспечивая при той же длительности процессов примерно одинаковую остаточную концентрацию органического углерода на уровне 9 мг/дм ${ }^{3}$ (степень очистки около 80\%). Гораздо лучшие результаты демонстрирует уголь ДПУ, исчерпывающий свою поглотительную способность к получасовому контакту фаз, приводя к остаточному содержанию органического углерода 0.9 мг/дм ${ }^{3}$ и демонстрируя степень очистки 97.8\%. Несколько превосходящие эти результаты обеспечивает использование угля МеКС, имеющего значительно большие по сравнению с углем ДПУ величины объема микропор (на 45-70 \%) и удельной поверхности (на 51-97 \%). Его адсорбционная способность, обусловливающая ту же длительность взаимодействия фаз, обеспечивает $98.8 \%$-ную очистку.

Значение величины ХПК для воды водоемов рыбохозяйственного назначения регламентировано 30 мг $\mathrm{O}_{2} /$ дм $^{3}$ [7]. Определение этого показателя пробы взятой сточной воды ОАО «Москокс», отобранной после 30-минутного контакта последней с углем ДПУ, привело к величине, составившей 15 мг $\mathrm{O}_{2} /$ дм $^{3}$. 
Результаты сопоставительного изучения динамики сорбции органических примесей, загрязняющих указанные стоки, в названных выше условиях активными углями ДПУ и БАУ характеризует информация, представленная на рис. 3.

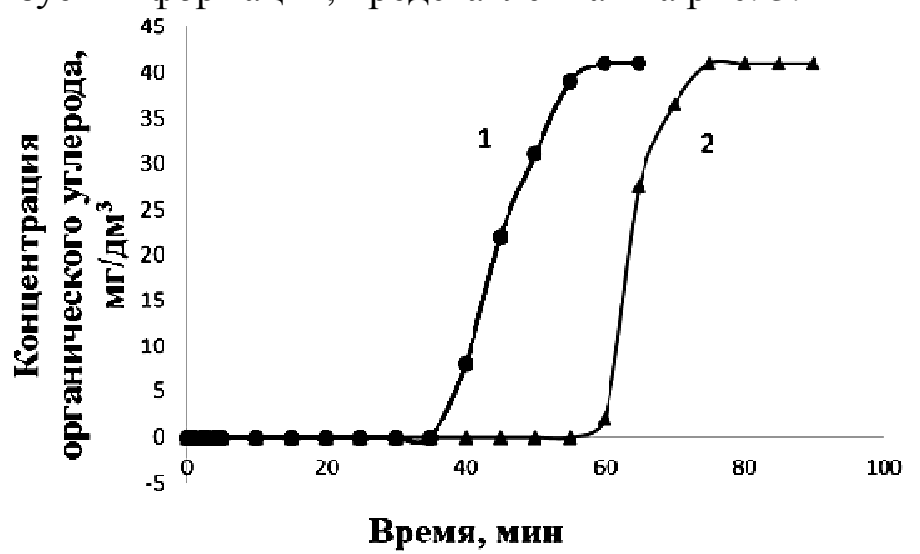

Рис. 3. Выходные кривые динамика адсорбции активными углями

$$
\text { (1 - БАУ, } 2 \text { - ДПУ) }
$$

Как следует из данных рис. 3, защитная мощность слоя зерен угля ДПУ практически в 1.5 раза превышает таковую зерен угля БАУ. Элементарными построениями и расчетами [12], связанными с выходными кривыми рис. 2, для углей ДПУ (числитель) и БАУ-А (знаменатель) определены величины коэффициентов симметричности выходных кривых $(0.40 / 0.48)$, работающего слоя $(7.94 / 13.3 \mathrm{~cm})$ и степени отработки адсорбционной емкости $\alpha(0.87 / 0.74)$, свидетельствующие о существенно большей эффективности использования угля ДПУ.

Таким образом, изложенные факты свидетельствуют о высокой конкурентоспособности активного угля ДПУ в решении задачи санитарной очистки охарактеризованных стоков.

\section{Заключение}

Показано, что активный уголь ДПУ, полученный из фрагментов вышедшей из эксплуатации мебели, является конкурентоспособным адсорбентом относительно аналогичных поглотителей на основе растительного сырья отечественного заводского производства, обеспечивающим возможность очистки от органических примесей сточных вод с территории коксохимического производства до санитарных нормативов.

Установлены рациональные условия углеадсорбционной обработки названных стоков при интенсивности перемешивания, соответствующей $\mathrm{Re}_{\mathrm{M}}=5 \cdot 10^{5}$ : доза адсорбента 1 г/дм ${ }^{3}$ и длительность контакта фаз 25-30 мин.

Реализация получения активного угля ДПУ в заводских масштабах может способствовать решению триединой задачи расширения номенклатуры углеродных адсорбентов, эффективного вовлечения в материальное производство практически не утилизируемых в настоящее время компонентов ТБО и сокращения негативного воздействия последних на окружающую среду.

\section{Список литературы}

1. Зубахин Н.П., Клушин В.Н., Дмитриева Д.А., Зенькова Е.В. // Кокс и химия. 2011. № 4. С. 39-42.

2. Зенькова Е.В., Рыжкова О.Д., Егорова Н.А. // «Экология России и сопредельных территорий», сборник трудов XVI Международной экологической студенческой конференции. 2011 г. Новосибирск. 2011. С. 191-192. 
3. Зенькова Е.В., Клушин В.Н., Осипова А.С., Егорова Н.А. и др. // Химическая промылиленность сегодня. 2016. № 2. С. 26-29.

4. Зенькова Е.В., Рыжкова О.Д., Клушин В.Н. // Успехи в химии и химической технологии. 2012. Т. 26. № 10 (139). С. 119-121.

5. Денисов В.В. Экология города. Ростов на Дону. МарТ. 2008. 832 с.

6. Родионов А.И., Клушин В.Н., Систер В.Г. Технологические прочессы экологической безопасности. Калуга. Издательство Н. Бочкаревой. 2007. 800 c.

7. Водный кодекс Российской Федерации. 2015. (редакция, действующая с 1 января 2016 года). Режим доступа http://docs.cntd.ru/document/vodnyj-kodeksrossijskoj-federacii-vk-rf (дата обращения 22.04.2016)

\section{References}

1. Zubahin N.P., Klushin V.N., Dmitrieva D.A., Zenkova E.V., Coke and Chemistry, 2011, No 4, pp. 39-42.

2. Zenkova E.V., Ryzhkova O.D., Egorova N.A. "Ecology of Russia and Adjacent Territories», Proceedings of the XVI International Ecological Student's Conference, , 2011, Novosibirsk, 2011, pp. 191-192.

3. Zenkova E.V., Klushin V.N., Osipova A.S., Egorova N.A., et al., Chemical industry today, 2016, No 2, pp. 26-29.

4. Zenkova E.V., Ryzhkova O.D., Klushin V.N., Achievements in chemistry and chemical technology, 2012, Vol. 26, No 10 (139), pp. 119-121.

5. Denisov V.V .City ecology. Rostov on Don, MarT Publ., 2008, 832 p.

6. Rodionov A.I., Klushin V.N., Sister V.G. Technological processes of ecological safety. Kaluga, N. Bochkarevoj Publ., 2007, 800 p.

Зенькова Елена Васильевна - аспирант РХТУ им. Д.И. Менделеева, Москва

Клушин Виталий Николаевич - профессор, д.т.н., профессор РХТУ им.Д.И. Менделеева, Москва

Зубахин Николай Петрович - начальник производственно-технического отдела Московского коксогазового завода, Видное

Семенов Геннадий Михайлович - профессор, д.т.н., профессор РХТУ им.Д.И. Менделеева, Москва

Осипова Анастасия Сергеевна - студент, РХТУ им.Д.И. Менделеева, Москва

Шабалина Александра Сергеевна - студент РХТУ им. Д.И. Менделеева, Москва
8. Мухин В.М., Тарасов А.В., Клушин В.Н. Активные угли России. М. Металлургия. 2000. $352 \mathrm{c}$.

9. Мухин В.М. Активные угли. Эластичные сорбенты. Катализаторы, осушители и химические поглотители на их основе. Номенклатурный каталог. М. Руда и металлы. 2003. $280 \mathrm{c}$.

10. Активированные угли для очистки жидкостей. Активированный уголь АГ-3. Режим доступа http://www.neorganika.ru/index.php/carbons/liq uid/24-prodakts/liquid/26-ag3(дата обращения 22.04.2016)

11. Лурье Ю.Ю. Аналитическая химия промышленных сточных вод. М. Химия. 1984. $448 \mathrm{c}$.

12. Кельцев Н.В. Основы адсорбиионной техники. М. Химия. 1984. 592 с.

7. Water code of the Russian Federation. 2015. (the edition operating since January 1, 2016) Available at: http://docs.cntd.ru/document/vodnyj-kodeksrossijskoj-federacii-vk-rf(accessed 22.04.2016)

8. Muhin V.M., Tarasov A.V., Klushin V.N. Active coals of Russia. Moscow, Metallurgija Publ., 2000, 352 p.

9. Muhin V.M. Active coals. Elastic sorbents. Catalysts, dehumidifiers and chemical absorbers on their basis. Nomenclature catalog. Moscow, Ruda i metally Publ., 2003, 280 p.

10. Absorbent carbon for purification of liquids. AG-3 absorbent carbon. Available at: http://www.neorganika.ru/index.php/carbons/liq uid/24-prodakts/liquid/26-ag3(accessed

\subsubsection{6)}

11. Lur'e Ju.Ju. Analytical chemistry of industrial sewage. M., Himija Publ., 1984, 448 p.

12. Kel'cev, N.V. Bases of the adsorptive equipment. M., Himija Publ., 1984, 592 p.

Zenkova Elena Vasilevna - post-graduate of MUCTR, Moscow, E-mail: zenkova-elena@ yandex.ru

Klushin Vitaly Nikolaevich - professor, doctor of technical sciences, professor of of MUCTR, Moscow

Zubakhin Nikolay Petrovich - chief of the

Production engineering department of Moscow Coke-Gas Works, Vidnoe

Semenov Gennadiy Mihailovich - professor, doctor of technical sciences, professor of of MUCTR, Moscow

Osipova Anastasia Sergeevna - student of MUCTR, Moscow

Shabalina Aleksandra S. - student of MUCTR, Moscow 